\title{
Genomic and immunologic factors associated with viral pathogenesis in a lethal EV71 infected neonatal mouse model
}

\author{
YINGYING YUE ${ }^{1}$, PENG LI $^{1}$, NANNAN SONG ${ }^{1}$, BINGQING LI ${ }^{1}$, ZHIHUI LI ${ }^{1}$, YUQI GUO ${ }^{1}$, WEIDONG ZHANG ${ }^{1}$, \\ MING Q. WEI ${ }^{2}$, ZHONGTAO GAI $^{3}$, HONG MENG $^{1}$, JIWEN WANG $^{4}$ and LIZENG QIN ${ }^{1}$ \\ ${ }^{1}$ Key Laboratory of Rare and Uncommon Diseases, Department of Microbiology, Institute of Basic Medicine, \\ Shandong Academy of Medical Sciences, Jinan, Shandong 250062, P.R. China; ${ }^{2}$ Division of Molecular and Gene Therapies, \\ Griffith Health Institute and School of Medical Science, Griffith University, Gold Coast, Queensland 4215, Australia; \\ ${ }^{3}$ Department of Comprehensive Internal Medicine, Jinan Children's Hospital, Jinan, Shandong 250022; \\ ${ }^{4}$ Department of Neurology, Shanghai Children's Medical Center, Shanghai Jiaotong University \\ School of Medicine, Shanghai 200127, P.R. China
}

Received June 24, 2015; Accepted March 7, 2016

DOI: $10.3892 / \mathrm{mmr} .2016 .5080$

\begin{abstract}
Hand, foot and mouth disease (HFMD) caused by enterovirus 71 (EV71) has emerged as a major health problem in China and worldwide. The present study aimed to understand the virological features of EV71 and host responses resulting from EV71 infection. Six different EV71 strains were isolated from HFMD patients with severe or mild clinical symptoms, and were analyzed for pathogenicity in vitro and in vivo. The results demonstrated that the six virus strains exhibited similar cytopathogenic effects on susceptible MA104 cells. However, marked differences in histological and immunopathological changes were observed when mice were inoculated with the different virus strains. Thus, the viruses studied were divided into two groups, highly or weakly pathogenic. Two representative virus strains, JN200804 and JN200803 (highly and weakly pathogenic, respectively) were studied further to investigate pathogenicity-associated factors, including genetic mutations and immunopathogenesis. The present study has demonstrated that highly pathogenic strains have stable genome and amino acid sequences. Notably, the present study demonstrated that
\end{abstract}

Correspondence to: Dr Lizeng Qin, Key Laboratory of Rare and Uncommon Diseases, Department of Microbiology, Institute of Basic Medicine, Shandong Academy of Medical Sciences, 18877 Jingshi Road, Jinan, Shandong 250062, P.R. China

E-mail: lizeng_qin@163.com

Dr Jiwen Wang, Department of Neurology, Shanghai Children's Medical Center, Shanghai Jiaotong University School of Medicine, 1678 Dongfang Road, New Pudong District, Shanghai 200127, P.R. China

E-mail: wangjiwen_99@hotmail.com

Key words: enterovirus 71, virulence, neurological damage, genomic mutation, immunopathogenicity a highly pathogenic strain induced a significant increase of the bulk CD4 $\mathrm{T}$ cell levels at 3 days post-inoculation. In conclusion, the current study demonstrates that genomic and immunologic factors may be responsible for the multiple tissue damage caused by highly pathogenic EV71 infection.

\section{Introduction}

Enterovirus 71 (EV71) is a major cause of hand, foot and mouth disease (HFMD) in children (1). The pathogen was initially recognized in 1969 in California following extensive outbreaks in the United States $(1,2)$. Subsequently, outbreaks have been recorded in Australia (3), Japan (4,5), Brazil (6), Malaysia (7), Thailand (8), Singapore (9), Taiwan (10) and mainland China $(11,12)$. When infected by EV71, the majority of patients recover naturally and generate neutralizing antibodies. However, there are certain patients who experience severe clinical symptoms, including aseptic meningitis, brainstem encephalitis, neurogenic pulmonary edema, acute flaccid paralysis, myocarditis and even mortality (13-15). The mechanisms underlying the difference in clinical severity remain unknown. Numerous factors affect the outcome of the disease during an EV71 infection epidemic, including genetic mutation of the virus and the immune status of patient.

Polioviruses and EV71 are members of the Enterovirus genus within the Picornaviridae family. The EV71 genome is a positive-stranded RNA containing 7,400 nucleotides. The genome includes an open reading frame, which encodes one polyprotein that is further divided into P1, P2 and P3 by the self-coding proteinases, $2 \mathrm{~A}$ and $3 \mathrm{C}$. $\mathrm{P} 1$ is further divided into four structural proteins, VP1-4. P2 and P3 contain the non-structural proteins $2 \mathrm{~A}, 2 \mathrm{~B}, 2 \mathrm{C}, 3 \mathrm{~A}, 3 \mathrm{~B}, 3 \mathrm{C}$ and $3 \mathrm{D}(16,17)$. The genome is flanked by $5^{\prime}$ and 3 ' untranslated regions (UTRs) (18). Studies investigating EV71 have previously demonstrated that amino acid mutations in VP2 and VP1 $(19,20)$, and a single nucleotide mutation in the 5'-UTR (21) increase infectivity and lethality. Furthermore, other reports 
demonstrated that cluster of differentiation (CD)4 T cells function in a helper role for B and CD8 T cell antiviral activities $(22,23)$, and induce immunopathogenesis elicited by viral infection (22). This suggests that CD4 T cells exhibit opposing functions in viral-induced immunity or immunopathogenesis.

The present study aimed to further characterize the interactions between viral pathogens and the induced host responses. The current study reports novel findings from two representative isolated virus strains with severe or mild clinical features, which were used to infect one-day-old mice. Results demonstrated that during EV71 infection viral genomic mutation and immunopathogenesis, potentially as a result of CD4 T cells, may lead to histological damage to multiple tissues. Thus, the current study has important implications for the identification of highly and weakly pathogenic strains, and in aiding the treatment and/or prevention of the EV71 infection.

\section{Materials and methods}

Cell culture and animals. All animal procedures were approved by the ethics committee of Shandong Academy of Medical Sciences (Jinan, China), and performed in compliance with the European Union regulations and the National Institutes of Health standards (1996 Guide for the Care and Use of Laboratory Animals) (24). BALB/c mice ( $\mathrm{n}=56$; weight, 1.2-1.5 g; age, 1 day) were purchased from Vital River Laboratories Co., Ltd. (Beijing, China). The animals were maintained according to the guidelines of the National Science Council of the People's Republic of China. Pups of the same experimental group were housed together in an environment of $50 \%$ humidity at $22^{\circ} \mathrm{C}$ under a 12 -h light/dark cycle. They were kept with their mothers to provide food. The MA104 cell line (25) (Cell Bank of Type Culture Collection of Chinese Academy of Sciences, Shanghai, China) was maintained at $37^{\circ} \mathrm{C}$ in a humidified atmosphere with $5 \% \mathrm{CO}_{2}$ in modified Eagle's medium (MEM; Invitrogen; Thermo Fisher Scientific, Inc., Waltham, MA, USA) containing $10 \%$ fetal bovine serum (FBS; Hyclone; GE Healthcare Life Sciences, Logan, UT, USA).

Patient sample collection. Human sample collection was approved by the research ethics committee of Jinan Infectious Diseases Hospital (Jinan, China). Fecal samples were collected from a representative healthy patient, and from 4 patients with mild and 2 with severe cases of HFMD between 2008 and 2010. Prior to collecting fecal samples, all parents or caregivers of the eligible children were asked to provide written informed consent and given an explanation of the study. Child assent was obtained from children $\geq 7$ years of age. Children were excluded if they and/or their caregivers refused study participation. The four mild cases exhibited fever $\left(<38^{\circ} \mathrm{C}\right)$ with rash on the hands, feet and buttocks, and ulcers on the mouth. The temperature of the patients returned to normal within 5 days and other symptoms disappeared in a short time. The 2 patients with severe cases experienced more severe symptoms. These included high fever $\left(>39^{\circ} \mathrm{C}\right)$ that lasted for 7 days, mild rash on the hands, feet and buttocks, and frequent vomiting. The conditions of the two severe cases developed rapidly with onset of pulmonary edema and neurologic complications, in addition to dyspnea, acute flaccid paralysis and coma.
Virus isolation and identification. The fecal samples were centrifuged at $10,000 \mathrm{x}$ g for $10 \mathrm{~min}$ at $4^{\circ} \mathrm{C}$ and filtered to produce a sterile suspension. MA104 cells $\left(1 \times 10^{6}\right.$ cells) were plated into a culture flask, incubated overnight to reach $65-70 \%$ confluence, and then infected with $0.5 \mathrm{ml}$ sterile suspension. Following adsorption for $2 \mathrm{~h}$, the virus suspension was replaced with MEM containing 2\% FBS. The culture medium was centrifuged at $10,000 \mathrm{x}$ g for $10 \mathrm{~min}$ at $4^{\circ} \mathrm{C}$. The virus was collected from the supernatant by three freeze-thaw cycles following the appearance of a $90 \%$ cytopathogenic effect (CPE) determined by observation of cell shrinkage, rounding of the cell, vacuolar changes and ecclasis using an ECLIPSE Ti-S microscope (Nikon Corporation, Tokyo, Japan). Total RNA was extracted from the virus supernatant using QIAamp Viral RNA Mini kit (Qiagen, Inc., Valencia, CA, USA), according to the manufacturer's protocols. Viral cDNA was obtained using Quantscript RT kit (Tiangen Biotech Co., Ltd., Beijing, China) for $1 \mathrm{~h}$ at $37^{\circ} \mathrm{C}$. Taq DNA polymerase (Tiangen Biotech Co., Ltd.) was used in the PCR, double distilled water served as a negative control and known EV71 cDNA served as a positive control. For identification of EV71, the standard primer sequences were adopted, as follows: Sense, 5'-GCA GCCCAAAAGAACTTCAC-3'; and anti-sense, 5'-ATTTCA GCAGGTTGGAGTGC-3'. The reaction was conducted using an MJ Mini Thermal Cycler (Bio-Rad Laboratories, Inc., Hercules, CA, USA) at the following conditions: $94^{\circ} \mathrm{C}$ for $3 \mathrm{~min} ; 30$ cycles of $94^{\circ} \mathrm{C}$ for $30 \mathrm{sec}, 55^{\circ} \mathrm{C}$ for $30 \mathrm{sec}$ and $72^{\circ} \mathrm{C}$ for $1 \mathrm{~min}$; and $72^{\circ} \mathrm{C}$ for $10 \mathrm{~min}$. The PCR products were separated using $2 \%$ agarose electrophoresis at $80 \mathrm{~V}$ for $40 \mathrm{~min}$, with a D2000 DNA ladder (Tiangen Biotech Co., Ltd.) and double distilled water as a negative control. The ethidium bromide was supplied by Sigma-Aldrich and the products were extracted with TIANgel Midi Purification kit (Tiangen Biotech Co., Ltd.), then sequenced by Beijing BioSune Biotechnology Co., Ltd. (Beijing, China).

Plaque purification. MA104 cells were seeded in a 24-well plate, incubated overnight and then infected with $200 \mu \mathrm{l}$ seri-

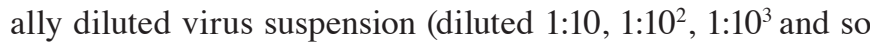
on). Following adsorption for $1 \mathrm{~h}$, the virus suspension was replaced with MEM supplemented with $2 \%$ FBS and $0.5 \%$ low melting agarose (Invitrogen; Thermo Fisher Scientific, Inc.). An independent plaque was collected with a crooked pipet at $48 \mathrm{~h}$ post-infection until a monolayer of MA104 cells formed.

Virus titration. Infectivity titer, described as tissue culture infectious dose 50 (TCID $\left._{50}\right)$, of the virus in MA104 cells $\left(1 \times 10^{5}\right.$ cells/well) was performed following the previously described method of Reed and Muench (26). Briefly, MA104 cells were seeded in 96-well plates at $1 \times 10^{4}$ cells/well. Following overnight incubation, the virus was serially diluted 10-fold with RPMI-1640 (Invitrogen; Thermo Fisher Scientific, Inc.) containing $2 \% \mathrm{FBS}$ and added to the monolayer MA104 cells. The plates were then incubated at $37^{\circ} \mathrm{C}$ in a $5 \% \mathrm{CO}_{2}$ atmosphere for $96 \mathrm{~h}$ and the presence of CPE was observed (27).

Viral infection of mice. Seven groups of eight 1-day-old BALB/c pups were inoculated with $1 \times 10^{4} \mathrm{TCID}_{50}$ of the different virus strains by intraperitoneal injection. One group was administered MEM containing 2\% FBS as a control. The mice were 
monitored every 3-6 h for clinical symptoms and were sacrificed by decapitation if mice met the following criteria: Body weight loss; lethargy; hypoxemia; and hypothermia, $<33.5^{\circ} \mathrm{C}$.

Electromyography determination. The function of nerves and quadriceps of the inoculated mice were examined using electromyography (Keypoint ${ }^{\circledR}$ G4 Workstation; Natus Medical Incorporated, Pleasanton, CA, USA). The responses of hind leg muscles were measured using $\mathrm{Ag}-\mathrm{AgCl}$ electrodes (Natus Medical Incorporated). Thirty motor unit potentials were selected on the same muscles.

Histological analysis. At day 4 post-inoculation of the virus isolates, tissues were obtained from the different groups of mice and processed for histological analysis. Various tissue samples, including the cerebrum, spinal cord, limb muscle, thymus gland, spleen, liver, lungs, kidney, stomach and intestines were removed from infected mice. The tissues were fixed with $4 \%$ formaldehyde (Sinopharm Chemical Reagent Co., Ltd., Shanghai, China) for $48 \mathrm{~h}$ and embedded in paraffin (Sinopharm Chemical Reagent Co., Ltd.). The 5- $\mu \mathrm{m}$ sections were stained with hematoxylin and eosin Y (Sigma-Aldrich, St. Louis, MO, USA) for morphological examination. The sections were observed under an ECLIPSE Ti-S microscope.

Immunohistochemical analysis. The 5- $\mu \mathrm{m}$ sections were placed on poly-L-lysine-coated (Sigma-Aldrich) glass slides and fixed with $4 \%$ paraformaldehyde (Sinopharm Chemical Reagent Co., Ltd.) in phosphate-buffered saline (PBS; Invitrogen; Thermo Fisher Scientific, Inc.). Endogenous peroxidase was inhibited by $3 \% \mathrm{H}_{2} \mathrm{O}_{2}$ (Sinopharm Chemical Reagent Co., Ltd.) in PBS. The sections were blocked with $5 \%$ bovine serum albumin for $1 \mathrm{~h}$ at $37^{\circ} \mathrm{C}$. EV71 was detected using mouse monoclonal anti-EV71 antibody (1:1,000; EMD Millipore, Billerica, MA, USA; cat. no. MAB979) followed by incubation with goat anti-mouse immunoglobulin G peroxidase-conjugated antibody (1:200; BIOSS, Beijing, China; cat. no. bs-0296G). The slides were then stained with 3,3'-diaminobenzidine (Sigma-Aldrich) and counterstained with hematoxylin for morphological examination using the ECLIPSE Ti-S.

Quantification of $T$ and $N K$ cells. At 0, 3, 7 and 12 days post-infection, spleens were excised from two of the mice from each group, then homogenized and the cells were harvested using 70- $\mu \mathrm{m}$ cell strainers (BD Biosciences, Franklin Lakes, NJ, USA). Splenocyte suspensions were centrifuged at $500 \mathrm{x} \mathrm{g}$ for $5 \mathrm{~min}$ at $4^{\circ} \mathrm{C}$ over Histopaque (Sigma-Aldrich) and washed. Peripheral blood mononuclear cell (PBMC) suspensions were prepared in PBS supplemented with $2 \%$ FBS (Hyclone; GE Healthcare Life Sciences, Logan, UT, USA). Staining was performed according to the antibody manufacturer's protocols (eBioscience, Inc., San Diego, CA, USA). Briefly, $\sim 1$ million PBMCs were stained for the cell surface molecules, CD4, using fluorescein isothiocyanate (FITC)-labeled rat monoclonal antibodies (1:200; eBioscience, Inc., cat. no. 11-0042), and CD25, using phycoerythrin (PE)-cyanine 5.5-labeled rat monoclonal antibodies (1:200; eBioscience, Inc.; cat. no. 35-0251), for $30 \mathrm{~min}$. They were then fixed and permeated using Cytofix/Cytoperm buffer (BD Biosciences) for the appropriate time according to the manufacturer's protocols. Other PBMCs were stained in parallel using APC-labeled rat monoclonal anti-CD16 (for NK cells; 1:200; eBioscience, Inc.; cat. no. 17-0161-81), rat monoclonal FITC-labeled anti-CD3 (for total lymphocytes; 1:200; eBioscience, Inc.; cat. no. 11-0032) and PE-labeled rat monoclonal anti-CD8 antibody (1:200; eBioscience, Inc.; cat. no. 12-0081). Cells were washed with $200 \mu 1 \mathrm{1X}$ Perm/Wash buffer (BD Biosciences) and stained with PE-labeled rat monoclonal forkhead box P3 (Foxp3) antibody (1:50; eBioscience, Inc.; cat. no. 12-5773) for $1 \mathrm{~h}$ at room temperature. The cells were washed again in $200 \mu 1 \mathrm{1X}$ Perm/Wash buffer and fixed in paraformaldehyde-PBS. Cells were then analyzed using a BD FACSCalibur ${ }^{\mathrm{TM}}$ flow cytometer (BD Biosciences) and FlowJo software (version 7.6.1; Tree Star, Inc., Ashland, OR, USA).

Full-length gene sequencing and analysis. The full-length sequencing of the virus genome was performed by Beijing BioSune Biotechnology Co., Ltd. and analyzed using Moleculat Evolutionary Genetics Analysis software (version 5.05) (28).

Statistical analysis. Student's t-test was used to determine statistical significance. All analyses were performed using SPSS software (version 13.5; SPSS, Inc., Chicago, IL, USA). $\mathrm{P}<0.05$ was considered to indicate a statistically significant difference.

\section{Results}

Six EV71 strains were isolated and a weakly and highly pathogenic strain were selected for further study. MA104 cells exhibited marked CPEs on day 1 following inoculation with viral specimens. The CPEs included cell shrinkage, rounding of the cell, cytoplasmic vacuolar changes and ecclasis. Six specimens exhibited similar CPE and all were identified as EV71 following inoculation. The present study identified a weakly (JN200803) and a highly pathogenic strain (JN200804; Fig. 1A).

No difference in virulence was determined by TCID $_{50}$ titration. The $\mathrm{TCID}_{50}$ of the six virus specimens were calculated according to the method previously described by Reed and Muench (26). The TCID ${ }_{50}$ of all viruses were between $10^{5.7}$ and $10^{6.1} / \mathrm{ml}$. No statistical significance was demonstrated between the TCID $_{50}$ titrations of different viral samples ( $P>0.05$; $t$-test).

Mice were infected with the weakly or highly pathogenic strains. One-day-old BALB/c mice were inoculated with $1 \times 10^{4}$ $\mathrm{TCID}_{50}$ from each virus strain by intraperitoneal injection. The data of two representative highly/weakly pathogenic viruses are presented. By day 3 post-infection, 4 out of 7 JN200804-infected mice had developed hind limb paralysis (Fig. 1B) and by day 4 post-infection, all JN200804-infected mice had developed hind limb paralysis and were sacrificed within 5-7 days post-infection (Fig. 1C). By contrast, the JN200803-infected and negative control mice remained healthy and grew normally without any apparent neurological symptoms.

Electromyography demonstrated an increased time limit and decreased wave amplitude in JN200804-infected mice. To further assess the function changes to the nerves and muscles following viral infection, an electromyography machine was 
A

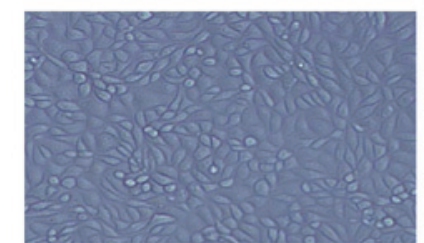

b

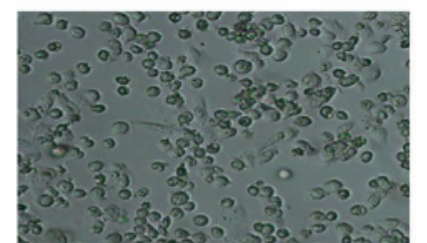

c

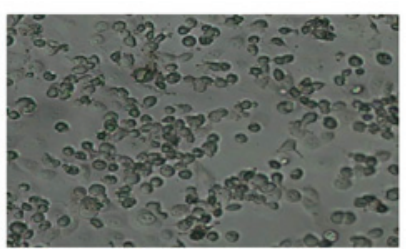

B

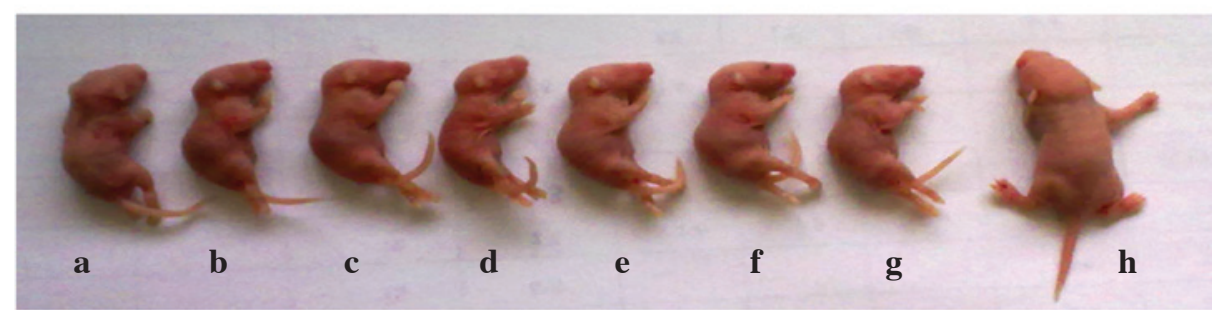

C
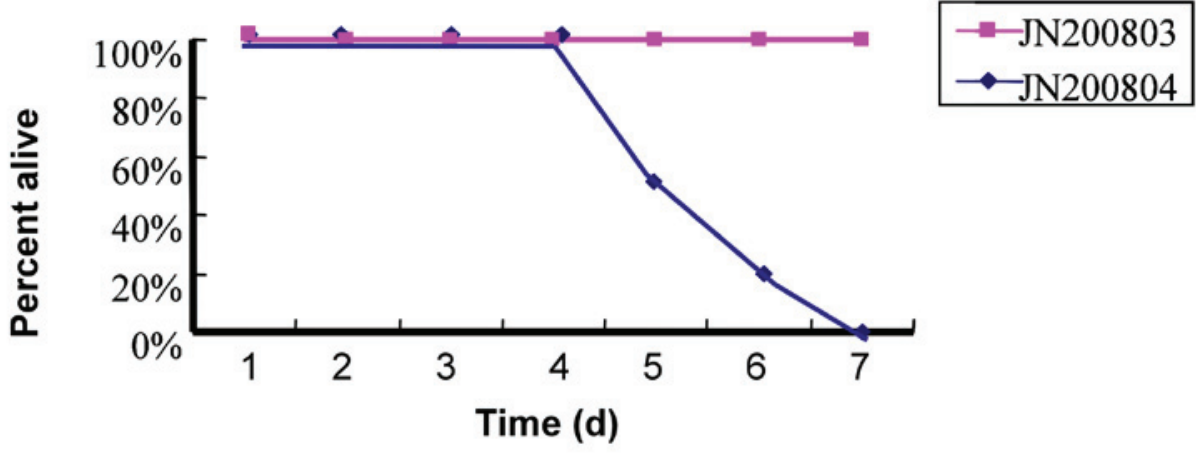

D
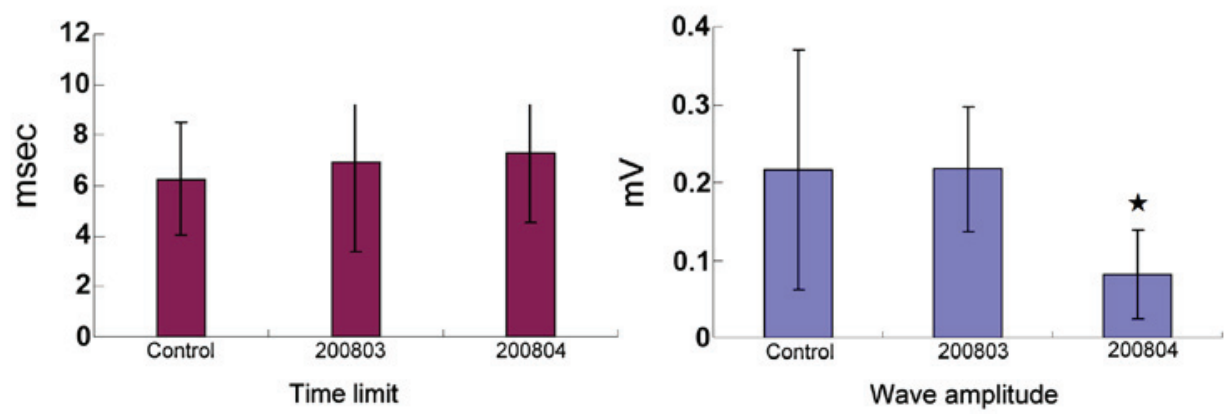

Figure 1. Enterovirus 71 isolation and the general status of mice following inoculation with viral isolates. (A) Cytopathogenic effect on MA104 cells (x100). (a) control cells; (b) cells infected with low pathogenic JN200803 strain; (c) cells infected with highly pathologic JN200804 strain. (B) Mice were inoculated with the two viruses. Mice a-g, JN200804-infected; mouse h, representative JN200803-infected mouse. (C) Survival curves following infection with JN200804 and JN200803 strains. (D) Electromicrography time limit and wave amplitude results of JN200804-infected and JN200803-infected mice. Data are presented as the mean \pm standard error. ${ }^{*} \mathrm{P}<0.05$ vs. control group. The results presented are representative of three experiments.

employed to record the electric current time limit and wave length. Electromyography of nerve and muscle function demonstrated that the time limit was increased and the wave amplitude significantly decreased in JN200804-infected mice compared with control mice $(\mathrm{P}<0.05)$, whereas, the JN200803-infected mice were normal with no statistical difference compared with the negative control ( $\mathrm{P}>0.05$; Fig. 1D).

Numerous histological changes were observed in JN200804-infected mice. Histological analysis was performed on a variety of tissues and major organs from EV71-infected mice (Fig. 2). Compared with negative control mice, numerous histopathological changes were observed in various tissues following JN200804 inoculation. The number of Purkinje and granular cells in the cerebellum were decreased compared with non-infected mice (Fig. 2A). Additionally, nerve fibers in the white matter of the spinal midpiece appeared thick and swollen (Fig. 2C), and pneumorrhagia was observed (Fig. 2E). Furthermore, lymphocyte infiltration and acidophilic degeneration were present in the liver (Fig. 2G). In the renal cortex, the number of glomeruli was decreased and epithelial cells within the kidney tubules appeared cloudy and were swollen in appearance (Fig. 2I). The skeletal muscle cells exhibited necrolysis with lymphocyte infiltration (Fig. 2K). However, the JN200803-infected mice did not demonstrate apparent histopathological changes (Fig. 2) when compared with negative controls.

Immunohistochemical analysis demonstrated the presence of EV71 in brain tissue samples from JN200804-infected mice. 
Table I. Sequence comparison of JN200803 and JN200804 strains.

\begin{tabular}{|c|c|c|}
\hline Region & Nucleotide sequence (JN200803>JN200804) & Amino acid sequence (JN200803>JN200804) \\
\hline \multirow[t]{3}{*}{ 5'-UTR } & $\mathrm{C} 115 \mathrm{~T}$ & -- \\
\hline & $\mathrm{T} 132 \mathrm{C}$ & -- \\
\hline & $\mathrm{T} 811 \mathrm{C}$ & -- \\
\hline \multirow[t]{3}{*}{ VP3 } & A2196G & Q485R \\
\hline & $\mathrm{C} 2253 \mathrm{~T}$ & A504V \\
\hline & G2351A & V537I \\
\hline VP1 & G2657A & G639S \\
\hline $2 \mathrm{~A}$ & G3551A & G937S \\
\hline \multirow[t]{3}{*}{$2 B$} & $\mathrm{C} 3783 \mathrm{~T}$ & A $1014 \mathrm{~V}$ \\
\hline & A3875G & I1045V \\
\hline & $\mathrm{C} 3927 \mathrm{~T}$ & T1062I \\
\hline \multirow[t]{4}{*}{$2 \mathrm{C}$} & A4146G & K1135R \\
\hline & G4177T & E1145D \\
\hline & $\mathrm{T} 4206 \mathrm{C}$ & V1155A \\
\hline & G4823A & V1361M \\
\hline \multirow[t]{2}{*}{$3 \mathrm{C}$} & A5531G & I1597V \\
\hline & G5591A & D1617N \\
\hline \multirow[t]{2}{*}{$3 \mathrm{D}$} & C5978T & L1746F \\
\hline & $\mathrm{C} 7179 \mathrm{~T}$ & A2146V \\
\hline 3'-UTR & A7347G & -- \\
\hline
\end{tabular}

There are 16 amino acid sequence variances in coding region and 4 nucleotide sequence variances in non-coding region between JN200803 and JN200804 strains. UTR, untranslated region.

A
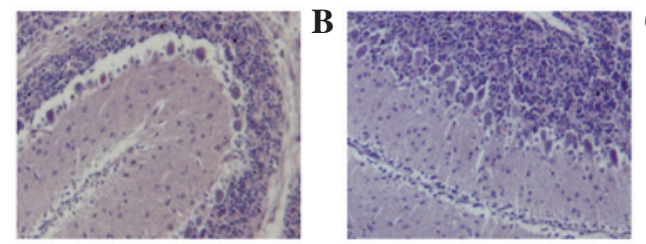

$\mathbf{E}$
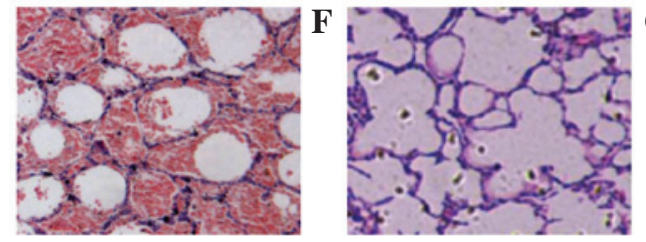

I
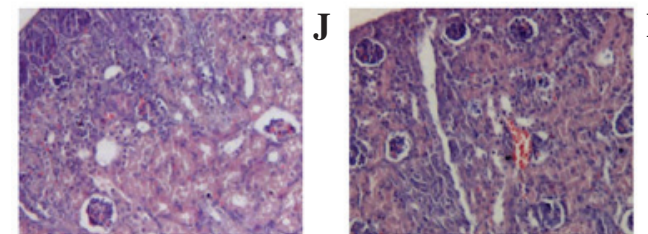
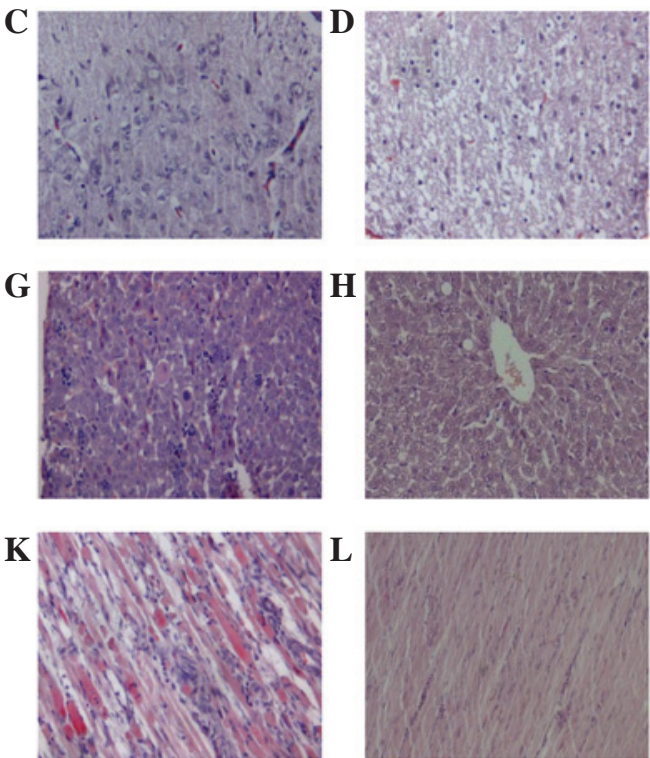

Figure 2. Histological examination of tissues from enterovirus 71-infected mice using hematoxylin and eosin staining. (A and B) Cerebellum, (C and D) spinal midpiece, (E and F) lung, (G and H) liver, (I and J) renal cortex and (K and L) skeletal muscle of JN200804-infected (A,C,E,G,I and K) and JN200803-infected (B,D,F,H,J and L) mice. In JN200804-infected mice, compared with negative controls, (A) the number of Purkinje cells and granular cells of cerebellum were decreased, (C) nerve fibers in white matter of spinal middle piece were thick, swollen looking. (E) Pneumorrhagia was also observed under microscope. (G) Lymphocyte infiltration and acidophilic degeneration was observed in the liver. (I) In the renal cortex, the number of glomeruli was decreased and epithelial cells within the kidney tubules appeared cloudy and swollen. (K) Necrolysis and lymphocyte infiltration was observed in skeletal muscle cells necrolysis with lymphocyte infiltration There was no apparent histopathological changes to the JN200803-infected mice compared with negative controls. The results presented are representative of two experiments.

Having observed broad histological damages to various tissues following infection with a highly pathogenic strain of EV71, mice also exhibited apparent neurological damage. Thus, the present study investigated whether the brain tissues were 
A

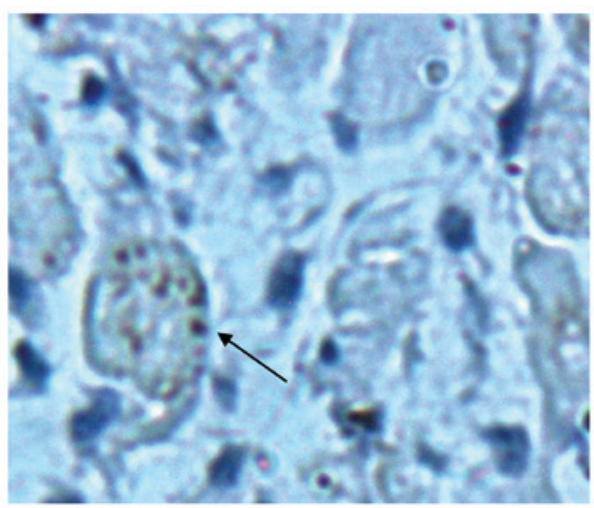

B

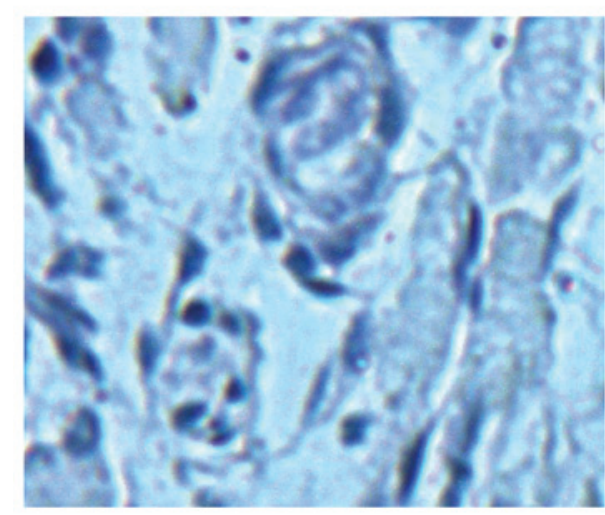

Figure 3. Immunohistochemical analysis. Immunohistochemistry staining of brain tissue from (A) JN200804-infected and (B) JN200803-infected mice. Arrows indicate enterovirus 71 antigen-positive cells (brown staining). The results presented are representative of two experiments. Staining used was 3,3'-diaminobenzidine and counterstaining with hematoxylin. Magnification, $\mathrm{x} 400$.

directly infected with the virus. Evidence of EV71 infection was confirmed by staining brain tissue sections from JN200804 and JN200803-infected mice with anti-EV71-specific antibody (Fig. 3). EV71 staining was observed in the brain tissue of JN200804-infected mice, but not in JN200803-infected mice. Negative control tissues did not exhibit any positive staining (data not shown).

Bulk CD4 T cell expansion was increased in highly pathogenic EV71 JN200804 strain-infected mice. Viral pathogens often induce strong $\mathrm{CD} 4 \mathrm{~T}$ cell responses that are characterized for their ability to aid B cell and CD8 T cell responses (20). However, a previous study has elucidated alternative pathogenic mechanisms by which vaccine-elicited CD4 T cells induce immunopathogenesis following chronic lymphocytic choriomeningitis virus (LCMV) infection (22). Thus, the present study investigated the CD4 T cell expansion levels during EV71 infection (Fig. 4). Notably, at day 3 post-JN200804 infection, the expansion of spleen bulk CD4 T cells was increased by 6 -fold compared with the weakly pathogenic (JN200803) strain $(\mathrm{P}<0.01)$. This result indicates that overexpansion of $\mathrm{CD} 4$ $\mathrm{T}$ cells may be an important factor in tissue damage following infection with highly pathogenic EV71 (Fig. 4). Furthermore, regulatory $T$ cells isolated from the spleen were also quantified by intracellular staining with Foxp3. No significant difference was observed in the level of Foxp3-positive cells between JN200804 and JN200803-infected samples. Additionally, no
A

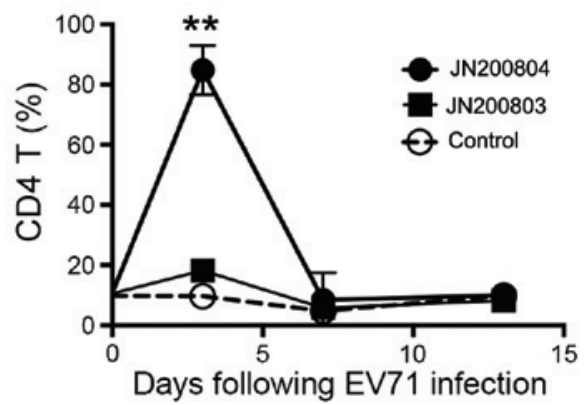

B

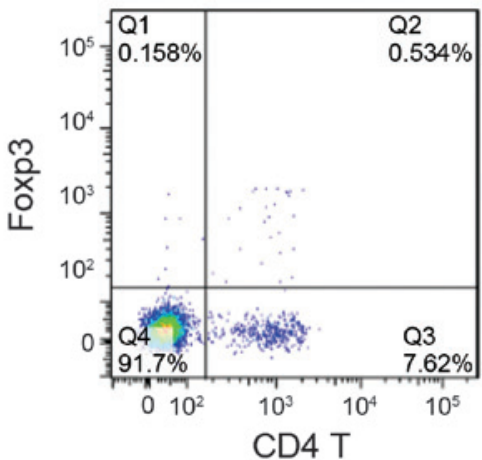

C

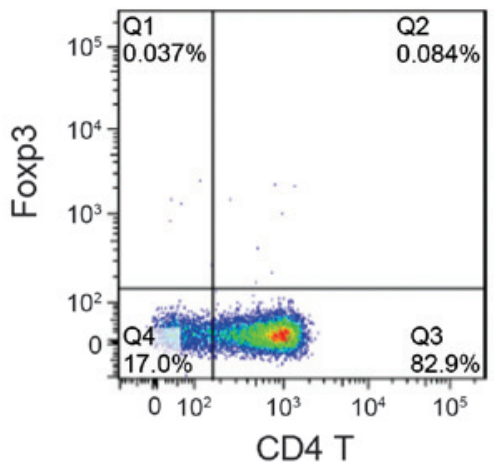

D

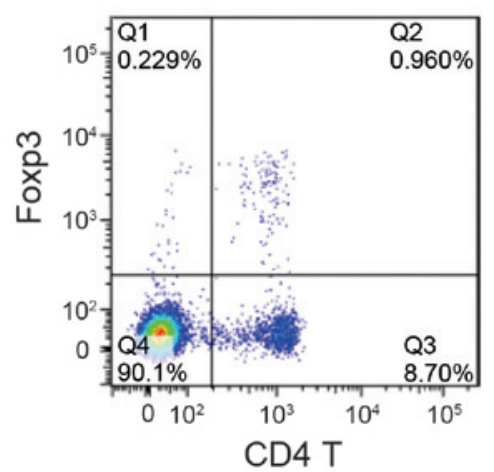

Figure 4. CD4 T cells expansion is increases in highly pathogenic EV71-infected mice. Mice ( $=5$ ) were inoculated with EV71 JN200803 and JN200804 strains $\left(1 \times 10^{4}\right.$ tissue culture infectious dose ${ }_{50}$, intraperitoneal injection), controls were injected with phosphate-buffered saline. At 0,3 , 7 and 12 days post-inoculation, spleens were isolated and homogenized. Splenocytes were stained with anti-CD4 and CD25 antibodies, and intracellularly stained with anti-Foxp3 antibodies. Flow cytometry and FlowJo software were used to analyze the CD4 T cells. (A) Kinetics of CD4 T cells expansion. A significant increase of CD4 T cell expansion was observed at 3 days post-inoculation with the highly pathogenic EV71 JN200804 strain. Representative flow cytometry analysis of CD4 T cell population in (B) uninfected mice, and mice 3 days post-inoculation with EV71 (C) JN200804 and (D) JN200803 strains. The results presented are representative of three experiments. Data are presented as the mean \pm standard error. ${ }^{* *} \mathrm{P}<0.01$ vs. JN200803. CD, cluster of differentiation; EV71, enterovirus 71; Foxp3, forkhead box P3. 
significant difference was observed in the levels of CD8 T or NK cells between JN200804 and JN200803-infected samples (data not shown).

Full-length gene sequencing and analysis indicated differences between the two strains in the non-coding and coding regions. Having demonstrated that the different virus strains resulted in either weakly or highly pathogenic changes in patients and animal models, the present study aimed to further investigate factors that may be leading to the differences. As viral genomic mutations can be a causative factor of various clinical differences, the two viruses were sequenced and the nucleotide sequences were analyzed. Sequence variation was detected at 106 nucleotide sequences, which included 4 nucleotide sequence variances in non-coding regions and 16 changes to the resulting amino acid sequence in the coding regions of the two strains (Table I). These sequences were deposited in GenBank (www.ncbi.nlm.nih.gov/genbank/) with the accession numbers JF913464 and HQ825317 for JN200803 and JN200804, respectively.

\section{Discussion}

EV71 infection has become a severe health problem for young children in China, and worldwide, due to frequent epidemics. The disease is typically mild and self-limiting in children, however, the infection may also result in severe neurological disease, which can be fatal. It is generally understood that the level of clinical severity depends on the patient's own health and immune status. Antibodies generated from a previous infection may protect patients from a later EV71 infection. Epidemiological studies have also demonstrated that the severity of HFMD is not directly associated with certain genotypes of EV71 (29,30). Thus, different genotypes may present with mild clinical symptoms and also severe complications at the same time. This finding is supported by research on the infections of cynomolgus monkeys. Previous results have demonstrated that monkeys inoculated with five EV71 strains isolated from individual patients with fatal HFMD encephalitis and meningitis all became infected and developed neurological manifestations within 1-6 days post-inoculation, irrespective of the inoculated strain used (31). This is in accordance with the results of the present study, as despite the TCID $_{50}$ of the two virus strains (JN200804 and JN200803) being similar in vitro, they induced starkly contrasting clinical features and pathogenicity when used to inoculate animals. The present study demonstrated that JN200804 infection resulted in a vast array of histological changes in major tissues and organs, and immunohistochemical analysis additionally demonstrated damage to brain tissues (Fig. 3). The current results are consistent with the findings discussed in a recent review (32); viral tropisms are completely distinct in the two viral strains investigated in the present study.

Viral infections are the result of coefficient interaction between a virus and host. One of the common features of RNA virus infection is genetic mutation, particularly for HIV and influenza viruses. This type of mutation is also a causative factor that leads to various clinical outcomes in HIV and viral influenza infections. Regarding EV71 infection, a previous report has demonstrated that mutations in the VP1 capsid proteins are responsible for the viral infectivity in vitro and virulence in vivo (19). Likewise, virulence loci of coxsachievirus and poliovirus have also been reported within the VP1 region (33). The full-length sequencing results of the current study demonstrated that one amino acid mutation existed between the two strains in the VP1 region (Table I). Although non-structural proteins are not essential in forming the basic frame of a viral particle, they are understood to be crucial for infection and replication. Currently, the virulence and infectivity as a result of genomic changes remain largely unknown. However, in EV71 infection, an increasing number of reports, including the present study (Table I), have demonstrated that mutations in different regions, including the 3'-UTR (18) and 5'-UTR (34,35), in structural $(19,36)$ and non-structural (37-42) protein coding regions are responsible for virulence and tissue tropisms. Further study will elucidate the genetic virulent points important for therapeutic and preventive applications. As such, the ongoing aim of the present research is to investigate mutation-associated virulence in an EV71-infected mouse model.

Viral infection also induces immunopathogenesis, particularly in CD4 $\mathrm{T}$ cells. A previous report by the Penaloza-MacMaster et al (22) has demonstrated that vaccine-elicited CD4 T cells increased tissue immunopathogenesis in response to LCMV (16). In support of this previous finding, the present study demonstrated that the level of CD4 T cells was significantly increased at day 3 following injection of mice with JN200804 (Fig. 4B), the highly pathogenic EV71 strain. This indicates an important function for CD4 T cell response-induced pathogenesis during EV71 infection. Thus, further research will focus on CD4 T cell function in order to explore the mechanisms by which $\mathrm{CD} 4 \mathrm{~T}$ cells result in immunopathogenesis during EV71 infection.

In conclusion, the results of the current study demonstrated the genomic variation, and the different clinical, histological CD4 T cell responses as a result of infection with the two EV71 strains. The results of the present study suggest that genomic and immunological factors may mediate the tissue damage caused by highly pathogenic EV71 infection. Thus, by characterizing highly and weakly pathogenic EV71 strains, the results of the present study have important implications regarding the treatment and prevention of EV71.

\section{Acknowledgements}

The present study was supported by the National Science and Technology Major Special Project (grant no. 2014ZX09509-001001008); the Shandong Provincial Natural Science Foundation (grant no. ZR2013HQ039); the Institute of Basic Medicine grant (grant no. 2014-2); Shandong Academy of Medical Sciences grant (grant no. 2014-11); the Department of Health and Family-plan Bureau (grant no. 2014WS0068); and Shandong Provincial College of Traditional Chinese Medicine Antiviral Collaborative Innovation Center (grant no. XTCX2014).

\section{References}

1. Schmidt NJ, Lennette EH and Ho HH: An apparently new enterovirus isolated from patients with disease of the central nervous system. J Infect Dis 129: 304-309, 1974. 
2. Alexander JP Jr, Baden L, Pallansch MA and Anderson LJ: Enterovirus 71 infections and neurologic disease - United States, 1977-1991. J Infect Dis 169: 905-908, 1994.

3. Gilbert GL, Dickson KE, Waters MJ, Kennett ML, Land SA and Sneddon M: Outbreak of enterovirus 71 infection in Victoria, Australia, with a high incidence of neurologic involvement. Pediatr Infect Dis J 7: 484-488, 1988.

4. Mizuta K, Aoki Y, Suto A, Ootani K, Katsushima N, Itagaki T, Ohmi A, Okamoto M, Nishimura H, Matsuzaki Y, et al: Cross-antigenicity among EV71 strains from different genogroups isolated in Yamagata, Japan, between 1990 and 2007. Vaccine 27: 3153-3158, 2009.

5. Iwai M, Masaki A, Hasegawa S, Obara M, Horimoto E, Nakamura K, Tanaka Y, Endo K, Tanaka K, Ueda J, et al: Genetic changes of coxsackievirus A16 and enterovirus 71 isolated from hand, foot, and mouth disease patients in Toyama, Japan between 1981 and 2007. Jpn J Infect Dis 62: 254-259, 2009.

6. da Silva EE, Winkler MT and Pallansch MA: Role of enterovirus 71 in acute flaccid paralysis after the eradication of poliovirus in Brazil. Emerg Infect Dis 2: 231-233, 1991.

7. Chan LG, Parashar UD, Lye MS, Ong FG, Zaki SR, Alexander JP, Ho KK, Han LL, Pallansch MA, Suleiman AB, et al; For the Outbreak Study Group: Deaths of children during an outbreak of hand, foot, and mouth disease in sarawak, malaysia: Clinical and pathological characteristics of the disease. Clin Infect Dis 31: 678-83, 2000.

8. Chatproedprai S, Theanboonlers A, Korkong S, Thongmee C, Wananukul S and Poovorawan Y: Clinical and molecular characterization of hand-foot-and-mouth disease in Thailand, 2008-2009. Jpn J Infect Dis 63: 229-233, 2010.

9. Shah VA, Chong CY, Chan KP, Ng W and Ling AE: Clinical characteristics of an outbreak of hand, foot and mouth disease in Singapore. Ann Acad Med Singapore 32: 381-387, 2003.

10. Liu CC, Tseng HW, Wang SM, Wang JR and Su IJ: An outbreak of enterovirus 71 infection in Taiwan, 1998: Epidemiologic and clinical manifestations. J Clin Virol 17: 23-30, 2000

11. Sun LM, Zheng HY, Zheng HZ, Guo X, He JF, Guan DW, Kang M, Liu Z, Ke CW, Li JS, et al: An enterovirus 71 epidemic in Guangdong Province of China, 2008: Epidemiological, clinical, and virogenic manifestations. Jpn J Infect Dis 64: 13-18, 2011.

12. Tan X, Huang X, Zhu S, Chen H, Yu Q, Wang H, Huo X, Zhou J, Wu Y, Yan D, et al: The persistent circulation of enterovirus 71 in People's Republic of China: Causing emerging nationwide epidemics since 2008. PLoS One 6: e25662, 2011.

13. Chang LY, King CC, Hsu KH, Ning HC, Tsao KC, Li CC, Huang YC, Shih SR, Chiou ST, Chen PY, et al: Risk factors of enterovirus 71 infection and associated hand, foot, and mouth disease/herpangina in children during an epidemic in Taiwan. Pediatrics 109: e88, 2002

14. Li CC, Yang MY, Chen RF, Lin TY, Tsao KC, Ning HC, Liu HC, Lin SF, Yeh WT, Chu YT and Yang KD: Clinical manifestations and laboratory assessment in an enterovirus 71 outbreak in southern Taiwan. Scand J Infect Dis 34: 104-109, 2002.

15. Chen KT, Chang HL, Wang ST, Cheng YT and Yang JY: Epidemiologic features of hand-foot-mouth disease and herpangina caused by enterovirus 71 in Taiwan, 1998-2005. Pediatrics 120 e244-e252, 2007.

16. Chen C, Wang Y, Shan C, Sun Y, Xu P, Zhou H, Yang C, Shi PY, Rao Z, Zhang B and Lou Z: Crystal structure of enterovirus 71 RNA-dependent RNA polymerase complexed with its protein primer VPg: Implication for a trans mechanism of VPg uridylylation. J Virol 87: 5755-5768, 2013.

17. Lu G, Qi J, Chen Z, Xu X, Gao F, Lin D, Qian W, Liu H, Jiang H, Yan J and Gao GF: Enterovirus 71 and coxsackievirus A16 $3 \mathrm{C}$ proteases: Binding to rupintrivir and their substrates and anti-hand, foot, and mouth disease virus drug design. J Virol 85: 10319-10331, 2011

18. Kok CC and Au GG: Novel marker for recombination in the 3'-untranslated region of members of the species Human enterovirus A. Arch Virol 158: 765-773, 2013.

19. Huang SW, Wang YF, Yu CK, Su IJ and Wang JR: Mutations in VP2 and VP1 capsid proteins increase infectivity and mouse lethality of enterovirus 71 by virus binding and RNA accumulation enhancement. Virology 422: 132-143, 2012.

20. Cordey S, Petty TJ, Schibler M, Martinez Y, Gerlach D, van Belle S, Turin L, Zdobnov E, Kaiser L and Tapparel C: Identification of site-specific adaptations conferring increased neural cell tropism during human enterovirus 71 infection. PLoS Pathog 8: e1002826, 2012.
21. Yeh MT, Wang SW, Yu CK, Lin KH, Lei HY, Su IJ and Wang JR A single nucleotide in stem loop II of 5'-untranslated region contributes to virulence of enterovirus 71 in mice. PLoS One 6: e27082, 2011.

22. Penaloza-MacMaster P, Barber DL, Wherry EJ, Provine NM, Teigler JE, Parenteau L, Blackmore S, Borducchi EN, Larocca RA, Yates KB, et al: Vaccine-elicited CD4 T cells induce immunopathology after chronic LCMV infection. Science 347 278-282, 2015.

23. Manzke N, Akhmetzyanova I, Hasenkrug KJ, Trilling M, Zelinskyy $\mathrm{G}$ and Dittmer U: $\mathrm{CD}^{+} \mathrm{T}$ cells develop antiretroviral cytotoxic activity in the absence of regulatory $\mathrm{T}$ cells and $\mathrm{CD} 8^{+}$ T cells. J Virol 87: 6306-6313, 2013.

24. National Research Council: Guide for the Care and Use of Laboratory Animals. 7th edition. National Academy Press, Washington, DC, 1996.

25. Cuadras MA, Arias CF and López S: Rotaviruses induce an early membrane permeabilization of MA104 cells and do not require a low intracellular $\mathrm{Ca}^{2+}$ concentration to initiate their replication cycle. J Virol 71: 9065-9074, 1997.

26. Reed LJ and Muench H: A simple method of estimating fifty per cent endpoints. Am J Hyg 27: 493-497, 1938.

27. Chua BH, Phuektes P, Sanders SA, Nicholls PK and McMinn PC: The molecular basis of mouse adaptation by human enterovirus 71 J Gen Virol 89: 1622-1632, 2008.

28. Tamura K, Peterson D, Peterson N, Stecher G, Nei M and Kumar S: MEGA5: Molecular evolutionary genetics analysis using maximum likelihood, evolutionary distance, and maximum parsimony methods. Mol Biol Evol 28: 2731-2739, 2011.

29. Shimizu H, Utama A, Yoshii K, Yoshida H, Yoneyama T, Sinniah M, Yusof MA, Okuno Y, Okabe N, Shih SR, et al: Enterovirus 71 from fatal and nonfatal cases of hand, foot and mouth disease epidemics in Malaysia, Japan and Taiwan in 1997-1998. Jpn J Infect Dis 52: 12-15, 1999.

30. Shih SR, Ho MS, Lin KH, Wu SL, Chen YT, Wu CN, Lin TY, Chang LY, Tsao KC, Ning HC, et al: Genetic analysis of enterovirus 71 isolated from fatal and non-fatal cases of hand, foot and mouth disease during an epidemic in Taiwan, 1998. Virus Res 68: 127-136, 2000.

31. Nagata N, Shimizu H, Ami Y, Tano Y, Harashima A, Suzaki Y, Sato Y, Miyamura T, Sata T and Iwasaki T: Pyramidal and extrapyramidal involvement in experimental infection of cynomolgus monkeys with enterovirus 71. J Med Virol 67: 207-216, 2002.

32. Muehlenbachs A, Bhatnagar J and Zaki SR: Tissue tropism, pathology and pathogenesis of enterovirus infection. J Pathol 235: 217-228, 2015

33. McMinn P, Lindsay K, Perera D, Chan HM, Chan KP and Cardosa MJ: Phylogenetic analysis of enterovirus 71 strains isolated during linked epidemics in Malaysia, Singapore, and Western Australia. J Virol 75: 7732-7738, 2001.

34. Thompson SR and Sarnow P: Enterovirus 71 contains a type I IRES element that functions when eukaryotic initiation factor eIF4G is cleaved. Virology 315: 259-266, 2003.

35. Klinck R, Sprules T and Gehring K: Structural characterization of three RNA hexanucleotide loops from the internal ribosome entry site of polioviruses. Nucleic Acids Res 25: 2129-2137, 1997.

36. Huang PN and Shih SR: Update on enterovirus 71 infection. Curr Opin Virol 5: 98-104, 2014.

37. Yang CH, Li HC, Jiang JG, Hsu CF, Wang YJ, Lai MJ, Juang YL and Lo SY: Enterovirus type $712 \mathrm{~A}$ protease functions as a transcriptional activator in yeast. J Biomed Sci 17: 65, 2010.

38. Cui S, Wang J, Fan T, Qin B, Guo L, Lei X, Wang J, Wang M and Jin Q: Crystal structure of human enterovirus 71 3C protease. J Mol Biol 408: 449-461, 2011.

39. Shih SR, Chiang C, Chen TC, Wu CN, Hsu JT, Lee JC, Hwang MJ, Li ML, Chen GW and Ho MS: Mutations at KFRDI and VGK domains of enterovirus $713 \mathrm{C}$ protease affect its RNA binding and proteolytic activities. J Biomed Sci 11: 239-248, 2004.

40. de Jong AS, de Mattia F, Van Dommelen MM, Lanke K, Melchers WJ, Willems PH and van Kuppeveld FJ: Functional analysis of picornavirus 2B proteins: Effects on calcium homeostasis and intracellular protein trafficking. J Virol 82: 3782-3790, 2008.

41. Tang WF, Yang SY, Wu BW, Jheng JR, Chen YL, Shih CH, Lin KH, Lai HC, Tang P and Horng JT: Reticulon 3 binds the $2 \mathrm{C}$ protein of enterovirus 71 and is required for viral replication. J Biol Chem 282: 5888-5898, 2007.

42. Choe SS, Dodd DA and Kirkegaard K: Inhibition of cellular protein secretion by picornaviral 3A proteins. Virology 337: 18-29, 2005. 